\title{
Getting to grips with social media as an academic: Supplementing your scholarly process
}

BOOK TITLE:

Social media for academics

\section{BOOK COVER:}

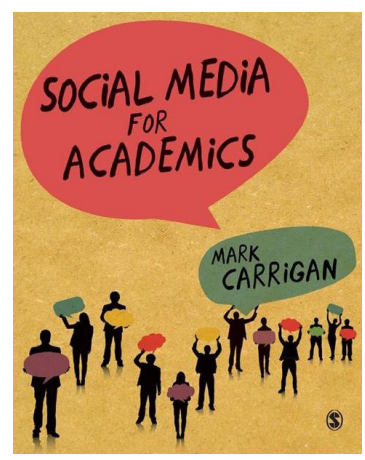

AUTHOR:

Mark Carrigan

ISBN:

9781473943704 (ebook)

\section{PUBLISHER:}

Sage Publications Ltd, London; USD39

\section{PUBLISHED:}

2016

\section{REVIEWER:}

Sarah Goodier

\section{AFFILIATION:}

Centre for Innovation in Learning and Teaching, Centre for Higher Education Development, University of Cape Town, Cape Town, South Africa

\section{EMAIL:}

sarah.goodier@uct.ac.za

\section{HOW TO CITE:}

Goodier S. Getting to grips with social media as an academic: Supplementing your scholarly process. S Afr J Sci. 2017;113(5/6), Art. \#a0208, 1 page. http://dx.doi. org/10.17159/sajs.2017/a0208
Social media are all around us. I can say with great certainty that you will have received at least one request from a family member, friend or colleague to join a social media platform. In Social Media for Academics, Mark Carrigan suggests that, instead of completely resisting this tidal wave of social media, you should investigate what aspects of it you can make work for you in your professional life.

While other aspects of information technology, such as Internet searches to gather information and emails to communicate with colleagues, have become common practice in academia, the use of social media is less pervasive. This book comes at an opportune time to help academics, researchers and postgraduate students who have been thinking about using social media in their professional lives to get started. The book also provides a useful way for those already engaged on social media to reflect on their goals and purposes and refine their approach.

The book is explicitly not a step-by-step training manual for the multitude of tools available. Rather it takes the view that while the technology may change rapidly, the underlying motivation for using technology remains the same - to become more effective academics. Carrigan focuses on how the technology can feed into academic purposes (e.g. teaching, communicating, sharing). Accordingly, the book is grounded within the discipline of digital scholarship and higher education (Chapter 1), approaching the topic from the perspective of how social media can potentially support and enhance the scholarly activity you already undertake. For those who have been focused on the practice of using social media in their academic endeavours, this book provides a useful introduction to some of the relevant theory and the academic writings on social media use.

The next four chapters are the most helpful for potential or new social media users. These chapters lay the groundwork for why, as an academic or researcher, you should care about social media and help you to come to grips with the suite of possible activities: publicising your work (Chapter 2), building your network (Chapter 3), engaging with the public (Chapter 4) and managing information (Chapter 5).

Although Carrigan does draw on experiences and practices of academics with certain social media tools in their professional lives, these activities - refreshingly - do not focus on a particular set of tools for the most part. Instead each chapter explores some of the possibilities of how you could begin to integrate social media activity into your pre-existing academic work to enhance your practice.

The later chapters explore the challenges that an academic social media user may face: professional identity (Chapter 6), communicating effectively (Chapter 7) and finding time for social media (Chapter 8). I would recommend these chapters specifically for those already using social media spaces as they provide a very useful point of reflection. In the final chapter (Chapter 9), the author explores a few potential scenarios for the future use of social media in higher education. The suggestions for further reading at the end of each chapter act as a useful guide to explore the particular topic further.

The book introduces many important ideas, issues and risks regarding the social media space, such as accessibility of the publications you share, the presence or absence of institutional social media policies and what they can enable and constrain, and the possibility of people engaging with you publically in an unpleasant way. While Carrigan may leave readers wanting to know more, introducing these concepts and challenges does help to flag areas that they may need to investigate further without overwhelming them.

A recurring piece of advice given in the book is to find a balance between what you want to get out of using social media and what you are willing (and able) to put into it in terms of time and energy. The book advises academics to think carefully about their purpose(s) in using social media (visibility, networking, outreach, etc.) and to set goals to help them check on whether they are achieving their original purpose. Finding what works for you, in your context, to achieve your purposes and goals is a key to successfully integrating social media into your working life.

Throughout the book, Carrigan shares the personal story of his move into and experience of the realm of social media as well as key insights from other academics and researchers using such media to communicate and connect professionally. This narrative approach, although sometimes weighted towards the author's experience of certain tools and scenarios, provides good food for thought. The experiences discussed in the book can help the reader to consider whether that approach might work for them in their own academic workflow. They highlight how certain social media tools could be connected to current practice in the research and publishing process, linking older methods of sharing academic work with the possibility of new online tools.

A concern regarding the approaches advocated in the book, especially for those in the Global South, is the general assumption of pervasive availability of (cheap) Internet access and connected personal devices. In contexts in which Internet and electricity are not necessarily widely available, cost-effective or reliable, several of the possibilities suggested in the book would be excluded or, at the very least, narrowed in scope. Yet the awareness of the possibilities as outlined in the book may still aid academics in such scenarios to better select the tools that are most appropriate for their context.

I recommend this book to academics, researchers and postgraduates who are using or thinking about using social media professionally as well as those interested in an introduction to the literature around social media use. It may also be of interest to media and communications departments and those involved in articulating policy around social media at higher education institutions. Even if you are a social media skeptic, you may find that you put down this book with a new perspective and an awareness of approaches that can help with your academic work in our increasingly digital and online world. 